\title{
Práticas educativas e prevenção de HIV/Aids: lições aprendidas e desafios atuais
}

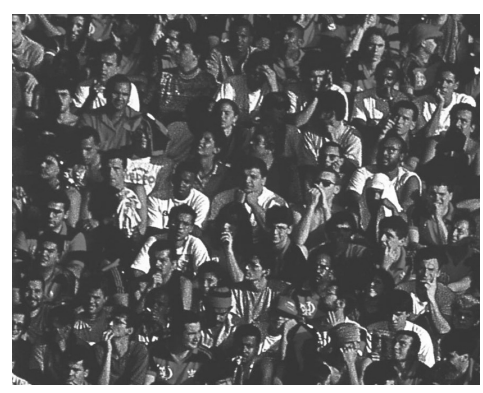

José Ricardo Carvalho Mesquita Ayres ${ }^{1}$

AYRES, J.R.C.M. Educational practices and the prevention of HIV/Aids: lessons learned and current challenges, Interface _ Comunic, Saúde, Educ, v.6, n.11, p.11-24, 2002.

Prevention has been a crucial aspect of Aids-control programs. Enormous progress both in knowledge and techniques in this area has been unable to significantly alter the basic determinants of the infection or the illness processes of substantial groups of people. This essay seeks to systematize the lessons learned in the field of prevention over the epidemic's two decades - taking into account, in particular, the Brazilian experience. The implications of these lessons in regard to our prevention strategies are, briefly: a) that we should think about prevention strategies less in terms of "population-based groups" and more in terms of something we can call "intersubjectivity contexts." This means demarcating areas of interaction (social, cultural etc.) that generate vulnerability, articulated with the intersubjective contexts that favor the construction of responses designed to reduce those vulnerabilities; b) the effective substitution of the molding attitude by an emancipatory attitude in our educational practices; c) that we should not focus the policies, programs and actions on risk groups or risk behaviors, but rather on the relationships socially established among the different social subjects and their interdependent and changeable identities.

KEY WORDS: Acquired immunodeficiency syndrome; health education.

A prevenção tem sido uma questão crucial para os programas de controle da Aids. Os enormes progressos do conhecimento e da técnica nesse campo não chegaram a alterar substantivamente os determinantes fundamentais da infecção e adoecimento de significativos contingentes populacionais. Neste ensaio busca-se sistematizar as lições que aprendemos no campo da prevenção nessas duas décadas de epidemia, tomando como base, em especial, a experiência brasileira. As implicações dessas lições para nossas estratégias de prevenção são, em síntese: a) que devemos pensá-las menos em termos de "grupo populacionais" e muito mais no que podemos chamar de "contextos de intersubjetividade”, isto é, delimitar espaços (sociais, culturais etc) de interação geradores de vulnerabilidade e, de modo articulado, os contextos intersubjetivos favoráveis à construção de respostas para a redução dessas vulnerabilidades; b) a efetiva substituição da atitude modeladora por uma atitude emancipadora em nossas práticas educativas; c) não centrar as políticas, programas e ações nos grupos ou comportamentos de risco, mas nas relações socialmente estabelecidas entre os diversos sujeitos sociais e suas interdependentes e cambiantes identidades.

PALAVRAS-CHAVE: Síndrome de imunodeficiência adquirida; educação em saúde.

\footnotetext{
${ }^{1}$ Professor do Departamento de Medicina Preventiva e Social, Universidade de São Paulo, USP. <jrcayres@usp.br>
} 
“Poderoso para mim não é aquele que descobre ouro. Poderoso para mim é aquele que descobre as insignificâncias (do mundo e as nossas)."

Manoel de Barros

\section{A prevenção hoje}

A prevenção tem sido, desde o início da epidemia, uma questão crucial para os programas de controle da Aids. Naqueles primeiros tempos, era grande o desconhecimento acerca da doença e sua distribuição e poucos os subsídios para guiar ações preventivas. Desde então, esse quadro sofreu profundas alterações. Houve um aumento substantivo do grau de conhecimento científico acerca do vírus, suas interações com o organismo, sua epidemiologia e sobre os principais determinantes sociais dessa epidemia. Destaca-se, em particular, o elevado grau de conhecimento alcançado acerca do controle dos efeitos danosos do HIV sobre o organismo humano.

Contudo, passados já vinte anos, e mesmo com todos os avanços apontados, a importância da prevenção não é menor nos dias de hoje. Os enormes progressos do conhecimento e da técnica não esvaziaram os desafios da prevenção, uma vez que tais avanços não chegaram a alterar substantivamente os determinantes da vulnerabilidade ao HIV e à Aids de significativos contingentes populacionais. Entre estes aspectos de vulnerabilidade, destacam-se a pobreza; a exclusão de base racial; a rigidez de papéis e condutas nas relações de gênero; a intolerância à diversidade, especialmente de opção sexual; o limitado diálogo com as novas gerações e a conseqüente incompreensão dos seus valores e projetos; o descaso com o bem estar das gerações mais idosas e a impressionante desintegração da sociedade civil no mundo globalizado (Castells, 1999), gerando uma violência estrutural que amalgama todos os demais aspectos de vulnerabilidade num perverso sinergismo (Farmer et al. 1996; Parker $\mathcal{E}_{\mathrm{r}}$ Carmargo Jr., 2000).

Mesmo onde os progressos técnicos e científicos fizeram sentir com mais intensidade seus notáveis efeitos, ainda não há lugar para descuido, nem por parte da população e nem dos profissionais de saúde. Este aspecto é especialmente relevante quando se trata dos avanços no tratamento. $\mathrm{O}$ progresso dos recursos diagnósticos e terapêuticos no manejo da Aids obriga a um concomitante reforço e exame crítico das ações de prevenção.

As modernas terapias antiretrovirais, quando associadas a uma informação extensiva, democrática e sustentada para o conjunto da sociedade e a serviços de saúde preparados, equipados e igualmente acessíveis ao conjunto dos cidadãos, têm determinado o fim da inexorável equação "infecção = morte", que marcou o início da epidemia. Uma imensa quantidade de pessoas vivendo com Aids recuperou plenamente, ou quase, sua capacidade de interagir, produzir, amar, ter prazer, etc. Novos infectados têm podido conviver com sua condição de soropositividade sem que isso chegue a afetar o mais essencial de seus projetos e estilos de vida. Uma geração inteira está chegando à adolescência vivendo com o HIV. 
2 TEIXEIRA, P. Comunicação pessoal. In:SEMINÁRIO INTERNACIONAL AIDS NAS GRANDES CIDADES. São Paulo, 2002.

${ }^{3}$ BASTOS, F. I. Comunicação pessoal. In:SEMINÁRIO INTERNACIONAL AIDS NAS GRANDES CIDADES. São Paulo, 2002.
Crianças brincam e estudam como seus pares. Mulheres e homens vivendo com Aids estão podendo, com segurança cada vez maior, serem mães e pais.

Os impactos da terapia antiretroviral não têm sido limitados, porém, à sobrevida e qualidade de vida dos já infectados ou doentes apenas. A perspectiva de poder se tratar e/ou conter o avanço da infecção é um estímulo a que cada vez maior número de pessoas, e mais precocemente, se preocupem com sua condição de saúde, procurem os serviços e permaneçam aderidos a seus cuidados. Nas palavras de Herbert de Souza (1994), o "Betinho", não é a perspectiva da morte que dá sentido a nossas existências, mas a perspectiva da vida mesmo. A possibilidade do tratamento constitui, com efeito, um poderoso motor para a melhora da prevenção.

Contudo, de modo concomitante aos impactos positivos citados, uma série de novas dificuldades veio se colocar em cena. É comum dizer-se que a possibilidade do tratamento pode produzir um "relaxamento" da população em relação à prevenção, mas já há evidências de que essa preocupação possa ser infundada. Recentemente, a coordenação nacional de DST/AIDS do Brasil revelou que seus estudos avaliativos não demonstram qualquer indício desta tendência nesses seis anos de política brasileira de acesso universal ao tratamento ${ }^{2}$, ainda que alguns estudos internacionais identifiquem essa associação, especialmente entre homossexuais jovens ${ }^{3}$. De qualquer forma, é inevitável que se atente para os efeitos dos novos significados sociais que se estão construindo sobre a infecção pelo HIV e a Aids neste contexto.

Renovados desafios se colocam para pesquisadores, técnicos e ativistas na identificação de novas representações, simbolismos, conteúdos não imediatamente verbalizados e, especialmente, da nova dinâmica epidemiológica que a doença pode assumir.

De fato, entre todas as importantes transformações trazidas pela era dos antiretrovirais, um aspecto da maior importância para a tarefa da prevenção é algo a que se poderia denominar de um "paradoxo epidemiológico". Trata-se de que, à medida que se avança na recuperação da saúde das pessoas vivendo com HIV, reduzindo as limitações que acabavam por apartá-las da chamada "população geral", mais freqüentes e diversificadas tenderão a ser as interações entre esses grupos. Se, por um lado, esse fato representa uma grande conquista no controle da epidemia, tanto do ponto de vista da assistência quanto da prevenção, conforme apontado, significa, por outro lado, que as oportunidades de transmissão do HIV por meio de relações sexuais, uso de substâncias injetáveis, gestação $e$ uso de hemoderivados poderão aumentar proporcionalmente. Por isso, se o controle da epidemia do HIV em nossos dias depende, em alto grau, da

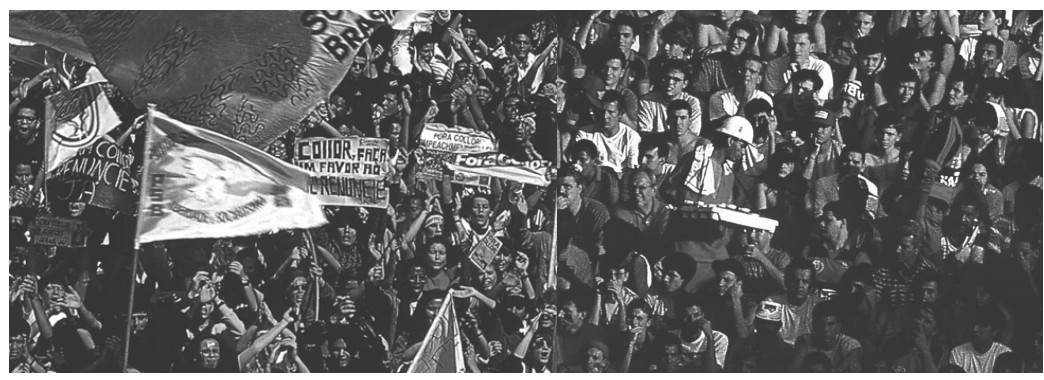

São Paulo, 1993

Rio de Janeiro, 1994 
eficácia dos antiretrovirais e de uma assistência à saúde de qualidade, é impossível não considerar que esse controle também depende radicalmente da construção de uma cultura preventiva ainda mais universalizada, sustentada, plural e versátil para o conjunto da sociedade.

Essa necessidade de intensificação e renovação traz para a prevenção novos cenários, sujeitos, experiências, valores, tornando-a ainda mais complexa. Por tudo que já se avançou no campo das respostas tecnocientíficas e sociopolíticas à epidemia, temos muitas razões para acreditar que é possível fazer avanços nessa direção, apesar das dificuldades apontadas. A contribuição que se pretende trazer com o presente ensaio caminha no sentido de inventariar alguns desses avanços e reexaminá-los criticamente, tendo no horizonte aqueles desafios.

Face ao conhecimento acumulado, o que profissionais e ativistas podem efetivamente fazer hoje, no sentido de favorecer a adoção de práticas protegidas e protetoras da infecção pelo HIV? Quais as implicações dos avanços terapêuticos sobre a concepção e o desenvolvimento dessas práticas? O que é preciso rever em nossas estratégias e recursos técnicos, para caminhar, realizar a renovação pretendida? Para desenvolver essa reflexão, buscar-se-á sistematizar um conjunto de aprendizados realizados no campo da prevenção nessas duas décadas de epidemia, tomando como base, em especial, a experiência brasileira. A proposta é apontar, a partir desse balanço, algumas implicações das atitudes e recursos emergentes desses aprendizados para o desenho de novas estratégias e métodos de prevenção.

Antes de prosseguir, cabem dois reparos. O primeiro é que a reflexão aqui proposta restringir-se-á às práticas educativas, pela centralidade que ocupam hoje no campo da prevenção, passando-se ao largo da questão de vacinas e das quimioprofilaxias, o que não significa, em absoluto, que se desconheça a relevância destes recursos. O segundo é que não se pretende fazer aqui uma lista exaustiva das diferentes estratégias e experiências em educação preventiva, nem qualquer tipo de hierarquização de sua relevância ou prioridade, mas tão somente um exercício de sistematização e reflexão.

\section{Lições aprendidas}

Primeira lição: terrorismo não funciona

A primeira lição aprendida, logo nos primeiros anos da epidemia, é que o caminho do terror, do susto, de que quanto mais assustadora a propaganda melhor seu efeito preventivo, é extremamente limitado. Essa via mostrou-se ineficiente, estéril, afastando mais que aproximando as pessoas do problema. Talvez tivesse bastado recorrer de forma mais precoce e conseqüente às teorias da comunicação para perceber que o cenário sombrio, apresentado por aquelas primeiras campanhas de prevenção, teria mesmo muita dificuldade de criar identidades, associações, motivações para que as pessoas mudassem seus comportamentos no momento das relações sexuais ou de fazer uso de drogas injetáveis.

É compreensível que, no início da epidemia, técnicos, militantes, formuladores de políticas, não tivéssemos mesmo condições de revisitar com 
mais tranqüilidade as teorias da comunicação, num momento em que se deparava com uma doença desconhecida, epidêmica e fatal. O correr dos anos e a experiência prática, porém, encarregaram-se de apontar a ineficácia dessas estratégias. Mais que isso, mostraram que o terror ajudava a gerar $e$ aumentar a discriminação e o preconceito e esses mostraram ser um dos mais perniciosos componentes da epidemia e um dos mais importantes elementos a serem combatidos (Treichler, 1991; Daniel, 1994).

No contexto dos avanços terapêuticos, a importância de recusar a estratégia do terror é ainda mais premente, pois é a cada dia maior o número de pessoas vivendo com Aids, às quais estaremos enganando, agredindo, desestimulando e desmobilizando ao associar tão

inexoravelmente a infecção pelo HIV ao sofrimento e à morte. Repita-se aqui Betinho. É a possibilidade da vida que nos leva a interagir, construir, planejar, não a certeza da morte.

Segunda lição: o risco é um conceito útil, mas limitado

Outra importante e difícil lição aprendida diz respeito às relações entre teoria e prática. Toda teoria em saúde nasce em estreita relação com processos de investigação empírica partindo, nesse sentido, de preocupações $e$ indagações diretamente relacionadas à prática. Resultados válidos $e$ consistentes dessas pesquisas transformam-se em conhecimento a partir de necessários processos de abstração e este conhecimento, ao retornar ao campo das práticas, pode assumir distintos graus de aplicabilidade e efetividade.

Desse modo, é preciso distinguir cuidadosamente os territórios de validade dos diferentes conceitos e de suas aplicações práticas, o que, com freqüência, é negligenciado. O uso que se faz da epidemiologia em saúde pública exemplifica esta dificuldade. Desde o início da epidemia recorreu-se à epidemiologia e seus estudos sobre riscos como uma instância que podia "legislar" quase absoluta sobre os determinantes do problema e construir respostas para sua solução. Desde a elaboração e teste de hipóteses de associação causal até a recomendação de quem devia fazer o que e quando, a epidemiologia tornou-se a depositária soberana de quase toda a esperança de controle da epidemia.

Ocorre que as análises de risco, como todo conhecimento epidemiológico, são também construídas à custa de sucessivos processos de abstração conceitual, que lhe garantem manuseio formal e matemático de grande precisão (Ayres, 1997). Porém, na medida mesma dessa precisão formal, dáse seu necessário afastamento de aspectos da realidade fundamentais para quem pensa a prevenção: a subjetividade, a significação, a interação, a dinamicidade (Ayres, 2001).

Tomar associações probabilísticas entre variáveis abstratas como principal, quando não única, orientação para ações de prevenção, centrando as estratégias de intervenção no "isolamento epidemiológico" dos chamados grupos de risco, ou na modelagem universal dos ditos comportamentos de risco, tem sido um erro freqüente. O primeiro porque rotula, generaliza, cristaliza, isola, paralisa. O segundo porque universaliza, dessubjetiva, despolitiza, descontextualiza. Ambos, usados acriticamente, conduzem à 
AYRES, J. R. C. M.

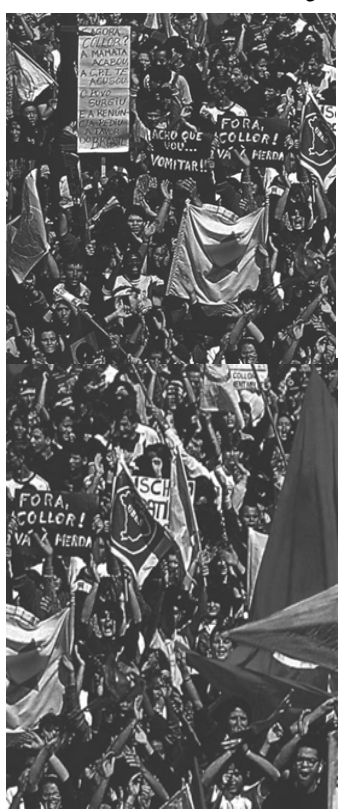

ineficácia, ineficiência e a violências de diversas ordens (Mann \& Tarantola, 1996).

Não se quer afirmar, com essas observações, que não haja qualquer sentido no uso de conceitos epidemiológicos, ao contrário. Para além de sua capacidade de gerar e testar hipóteses consistentes e relevantes para o conhecimento teórico da Aids, alguns impactos práticos imediatos são evidentes: o conceito de grupo de risco é apontado por alguns militantes gays como um fator que propiciou a organização da resposta política do grupo nos Estados Unidos; alguns técnicos sustentam que o raciocínio probabilístico é ainda o mais efetivo para orientar o controle dos bancos de sangue; com base na identificação de comportamentos de risco foram desenvolvidas técnicas educativas importantes, amplamente utilizadas nas oficinas de sexo seguro. É preciso, entretanto, atentar sempre para os critérios que tomamos por base para definir $x$ ou y como grupos de risco, e quais as implicações práticas dessa definição; saber se não existem outros recursos e estratégias, às vezes menos imediato, porém mais legítimos e éticos para alcançar o objetivo da prevenção; ou ainda quais as condições concretas - emocionais, morais, culturais, econômicas etc. - que os indivíduos têm para efetivamente adotar ou evitar comportamentos que o expõem ao HIV.

Subsumir as idéias de grupo de risco e comportamento de risco à noção mais abrangente de vulnerabilidade; tomar os Direitos Humanos como critério fundamental para identificar e combater as diversas vulnerabilidades - tais como as listadas ao início do artigo - e adotar a redução de danos como atitude orientadora de nossas intervenções preventivas constituem as mais expressivas respostas que emergiram desse aprendizado (Parker, 2000; Ayres et al., 1999).

Terceira lição: prevenção não se ensina

Pode parecer paradoxal, quando se disse logo ao início que a reflexão seria centrada na via educativa da prevenção, que se liste entre as lições aprendidas que prevenção "não se ensina". O ponto que se quer enfatizar com essa afirmação provocativa é que, rigorosamente, ninguém ensina nada a ninguém, mas todos aprendem com todos (Freire, 2000). Pesquisadores, militantes, técnicos, todos já investimos muito tempo e energia julgando poder "ensinar" às pessoas o que é o HIV, a Aids, as formas de se proteger da infecção. Entretanto, viu-se freqüentemente que as estratégias educativas e seus métodos de avaliação não passavam da superfície do problema. É como atirar pedras em lagos escuros. Produz-se um abalo de superfície, observam-se as efêmeras ondulações provocadas e perde-se de vista onde a pedra vai parar e o que realmente acontece com ela.

De novo, demorou-se a recorrer a algumas teorias iluminadoras. Mesmo no Brasil, a pátria de Paulo Freire, esse importante filósofo e metodólogo da educação, modelos bastante limitados e limitantes de educação preventiva foram amplamente importados e utilizados. Modelos orientados por uma idéia de comunicação unidirecional, dogmática e autoritária; modelos 
baseados na idéia de aprendizado como simples aquisição de informação; modelos centrados na modelagem do outro à própria imagem como objetivo da educação preventiva (Paiva, 2002).

Até pela natureza das questões postas em jogo quando a consideração dos comportamentos é incluída na esfera mais ampla das vulnerabilidades, não se pode esperar que a simples transmissão de uma informação modele o educando à vontade do educador. É preciso estabelecer uma relação tal entre educadores e educandos que permita a estes entrar efetivamente em contacto com a questão em pauta, para que ambos possam apreender o que se trata, de fato, e o que deve e pode ser feito a respeito (Seffner, 2002).

Foi assim que a comunidade gay norte-americana trocou as estéreis estratégias de abstinência pelo "safer sex", ou sexo mais seguro. Foi assim que se "reinventou" ali a camisinha como parte das relações sexuais. É assim que, no Brasil, em particular, estamos fazendo das oficinas de treinamento para "dizer não" (não ao sexo sem camisinha, não ao uso de drogas etc.) atividades de reflexão e organização para que se possa saber quando $e$ porque temos dificuldade de dizer não. É assim, ainda, que também se tem tentado transformar as "palestras" para transmissão de informação em "grupos de reflexão", buscando fomentar a construção de processos de emancipação de pessoas e grupos (Paiva, 2002).

Quarta lição: não somos sem um Outro

Há ainda uma quarta lição, talvez a mais recente e difícil delas, que pode ser resumida na afirmação de que aprendizado é encontro. De fato, o que caracteriza a educação no sentido pleno da palavra não é a simples preocupação de um sujeito diante de um objeto (o objeto de trabalho do educador), por mais cuidadosa que seja a delimitação desse objeto. Educar é perceber e trabalhar com a efetiva presença de "um sujeito diante de outro sujeito". Justificando a presença de um diante do outro, realizando mesmo a possibilidade dessa mútua presença, encontra-se, sim, um objeto, o objeto de aprendizado. Esse objeto, contudo, só vai ganhar plenamente sentido, para ambos, na efetividade do encontro educativo. O objeto é mesmo a razão da interação, mas é o diálogo entre os sujeitos que caracteriza a ação educativa propriamente dita.

Após duas décadas de epidemia, o que parece mais claro é o alcance radical dessa dimensão dialógica no pensar a educação. $O$ principal aprendizado é que, mais que um elemento puramente processual, o diálogo caracteriza as identidades mesmas de educador e educando. Isto é, o caráter substantivamente intersubjetivo não caracteriza apenas o processo educacional, mas estende-se à construção de nossas identidades de um modo geral. Nós somos porque o Outro é, nós somos à medida que o Outro é; nós não somos senão diante de um Outro.

O que se quer defender aqui, em síntese, é uma revisão filosófica - com base em já sólidos desenvolvimentos, cujos conteúdos e significados não se pode explorar mais amplamente no espaço deste artigo, como as de Ricoeur (1991), Habermas (1990), Rorty (1988), Gadamer (1996) - que leve à superação da concepção clássica de sujeito, apoiada nas concepções solipsistas e universalistas herdadas do iluminismo. Postula-se a necessidade 
premente de uma conceituação de subjetividade (subjetividade querendo denotar aqui simplesmente o ato ou estado de ser sujeito) em que a dimensão identitária seja definida por sua contínua reconstrução na e pela interação $0^{4}$.

A posição aqui adotada é a de que não existe o sujeito "individual", ou antes, que aquilo que tratamos como individualidade no sujeito, não é menos nem mais que o resultado de não estarmos sozinhos no mundo, de sermos sempre e imediatamente "o outro de cada um" (Ricoeur, 1991). É a partir da "resistência" do outro fora de nós que nos identificamos. É essa alteridade vivida que nos leva a atribuir a nós mesmos o predicado de indivíduo. Mas o In-dividuu, o que não se pode dividir, o que permanece coeso, não é sempre "o mesmo". Se é do outro que vem a resistência, se são sempre diferentes os predicados que, ao atribuirmos a terceiros, nos identificam, então essa individualidade não pode ser "mesmidade" (o mesmo), mas "ipseidade" (pelo mesmo) (Ricoeur, 1991).

Isto é, o que permanece no tempo não é sempre um e mesmo predicado que nos define como sujeitos, mas uma auto-diferenciação que se afirma a cada vez que reconheço um outro, o que leva Heidegger (1995) a distinguir a individualidade/eu da individualidade/si. Esta última guarda o sentido forte de sujeito, no sentido de ipseidade. Segundo esse filósofo, quando estamos falando de sujeitos referimo-nos a essa identidade-si, ao Eu que é "a cada vez meu", à ipseidade.

O que ocorre nas práticas de saúde é que o sujeito é predominantemente tratado como um ente individual e permanente, como mesmidade. Ao se perder de vista, em conceitos e práticas, a ipseidade dos sujeitos, torna-se mais difícil chegar ao âmago dos processos mais vivos de sua constituição enquanto tal. Assim, paradoxalmente, são perdidas as mais ricas possibilidades de participar da construção de identidades e de fortalecer $o$ poder transformador de indivíduos e grupos no que se refere à saúde.

A importância do giro que representa essa concepção imediatamente relacional de nossas identidades não é nem um pouco desprezível. Se o eu é a cada vez meu, o educador é também a cada vez um, determinado pelo aprendizado que advém de uma certa possibilidade de encontro com um outro, o que inclui, necessariamente, as circunstâncias desse encontro espaciais, temporais, morais, políticas, entre outras. Um excelente exemplo sobre a importância de quem se encontra, onde se encontra e como se encontra, para a determinação de quem somos e o que fazemos, pode ser encontrado no relato de uma educadora do Rio Grande do Sul ${ }^{5}$, durante um seminário organizado pela ABIA, no Rio de Janeiro. Tratava-se de um trabalho de prevenção de Aids entre travestis, trabalhadoras do sexo, na área metropolitana de uma grande cidade. O trabalho educativo mais relevante naquele momento não era com as travestis, mas com a polícia, que, ao reprimir a atividade profissional daquelas, impossibilitava também o trabalho de prevenção. Contou essa educadora que, após infrutíferas tentativas de "informar" os policiais sobre a importância da não repressão, da não violência e da abertura para o trabalho preventivo na área, educadores e travestis resolveram mudar sua estratégia. Certa vez, em plena luz do dia, todas se arrumaram a rigor e foram visitar nada mais nada

\author{
${ }^{4}$ A discussão acerca da \\ construção da \\ subjetividade e sua \\ relação com as \\ interações abarcam um \\ campo muito amplo de \\ disciplinas e autores, \\ com destaque para \\ Freud, de cuja obra \\ parte substantiva de \\ tudo que se escreve em \\ nossos dias sobre o \\ assunto é em parte \\ tributária. No entanto, \\ em função das \\ limitações do autor e \\ restringindo-nos às \\ necessidades mais \\ imediatas de nossa \\ argumentação, nos \\ fixaremos apenas nas \\ abordagens mais \\ propriamente \\ filosóficas da questão \\ $e$, entre elas, aquelas \\ relacionadas às \\ principais vertentes \\ hermenêuticas da \\ filosofia \\ contemporânea.
}

\author{
${ }^{5}$ LOURO, G. L. \\ Comunicação pessoal. \\ In: SEMINÁRIO \\ VIOLÊNCIA \\ ESTRUTURAL, \\ DESIGUALDADE \\ SOCIAL E \\ VULNERABILIDADE \\ FRENTE AO HIV/ \\ AIDS. Rio de Janeiro, \\ 2000.
}


menos que o Batalhão da Polícia Militar da região. A entrada do grupo, como cidadãs plenas, fazendo ecoar no pátio de entrada o barulho dos seus saltos altos, rumo ao gabinete do comandante para uma audiência, deixou paralisados os soldados. Paralisados mas solícitos. Dentro de pouco tempo estavam todos sentados, tomando um cafezinho oferecido pelo comandante, discutindo a melhor forma de solucionarem os impasses de sua difícil convivência.

O que o exemplo mostra é que mesmo identidades socialmente tão distintas e conflituosas, como as de policiais e travestis, podem ser reconstruídas em contextos de encontro diversos. Aqui fez toda a diferença o espaço físico, a luz do dia $e$ a nova situação geradora da presença de um diante do outro. O mesmo raciocínio pode ser estendido a outros processos conformadores de identidades, centrais no controle da epidemia de Aids, como a exclusão social, as relações de gênero, a violência etc.

\section{Caminhos a percorrer}

Por tudo o que já foi dito, parece claro que estão postas algumas sugestões de como enfrentar os desafios da prevenção da Aids em nossos dias. Em primeiro lugar, deve ser enfatizado que talvez já seja a hora dos educadores pensarmos nossas estratégias de prevenção menos em termos do grupo populacional objeto de nossa intervenção e muito mais no que podemos chamar de "contextos de intersubjetividade". Parece, com efeito, mais e mais sem sentido falar de prevenção para determinadas "populações-alvo". São modalidades particulares de encontro o que melhor define o que se deve e se pode esperar da intervenção.

A assunção de identidades (e práticas) intersubjetivamente construídas obriga a repensar não só espaços e estratégias de intervenção, mas também os contextos intersubjetivos nos quais se efetiva a vulnerabilidade ao HIV das pessoas com quem queremos trabalhar. Para exemplificar, uma população de jovens pobres, mas que vivam em uma comunidade onde a preocupação pública com sua exposição ao HIV seja ativamente expressa em ações de assistência à saúde, educação e suporte social de modo geral, estatal ou não, pode estar muito menos vulnerável que outra, de jovens economicamente mais favorecidos, mas na qual a ameaça da epidemia não tenha visibilidade ou resposta política. De outro lado, ainda que considerando que a pobreza é um poderoso determinante de vulnerabilidade, é preciso considerar que, mesmo em populações pobres há diferenciais internos de extrema relevância, por exemplo, grau de escolarização, cultura religiosa, origem étnica, aspectos que, vistos na dinâmica conformadora de intersubjetividades, devem sempre ser considerados.

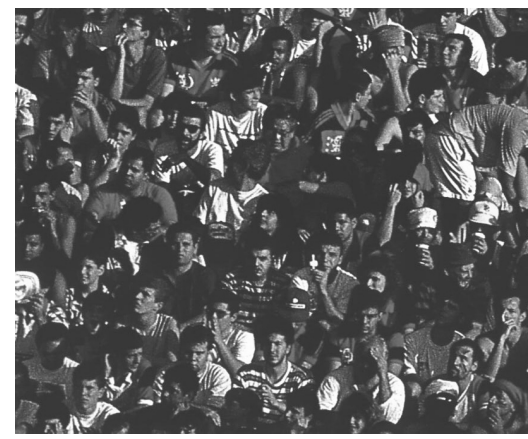

Definir contextos intersubjetivos geradores de vulnerabilidade e, de modo articulado, contextos intersubjetivos favoráveis à construção de respostas para a redução dessas vulnerabilidades constitui, portanto, um dos mais novos e decisivos desafios para a prevenção.

Quanto a este aspecto, seria interessante destacar a importância de se considerar ainda a presença, conhecida ou não, de pessoas vivendo com Aids 
entre aqueles com quem se vai trabalhar. Estejam estas explicitamente postas ou não, uma efetiva compreensão das necessidades e potencialidades das pessoas vivendo com HIV e Aids nas diversas comunidades é extremamente relevante para potencializar coalizão e solidariedade ou, em caso negativo, alimentar isolamento e indiferença. De outro lado, não se pode esquecer que a vulnerabilidade que levou os indivíduos a se infectarem não desaparece, embora, às vezes, se modifique um pouco, em função da nova condição. Os soropositivos não vivem em outro mundo. Seus contextos de interação intersubjetiva permanecem muito pouco alterados em relação à situação em que se infectaram, especialmente se recebem uma atenção à saúde que se limita ao tratamento medicamentoso, deixando de lado o cuidado com a qualidade de vida, de forma mais ampla (ECI, 2001).

Por isso, os espaços de tratamento também precisam ser pensados simultaneamente como espaços de prevenção. Talvez a estratégia mais sensível para detectar contextos vulnerabilizadores e possibilidades de construção de respostas sociais seja trabalhar mais conseqüentemente, e sob os novos enfoques acima citados, a questão da prevenção secundária.

Outro desafio importante é a efetiva substituição da atitude modeladora por uma atitude emancipadora nas práticas educativas; deixar de ser detentor do saber e passar a ser mediador para o saber. Aqui também a idéia de contextos de intersubjetividade pode ser útil. Pensar qual o contexto mais favorável à simetria entre educador e educando, ao efetivo compartilhamento de problemáticas e à criatividade individual e comunitária na busca de soluções, e escolhê-los como estratégia frente a outros mais facilmente modeladores, é um modo de enfrentar este desafio.

Sem lançar mão exatamente desse conceito, as práticas preventivas têm recorrido com sucesso à educação por pares. É possível que uma das explicações desse sucesso seja o fato de que este tipo de interação intersubjetiva seja mais favorável a uma educação emancipadora, não só devido à maior tendência à não imposição de modelos, pela maior chance de simetria entre educador e educando, mas também porque valores, projetos $e$ obstáculos são mais facilmente compartilháveis. Portanto, não parece se tratar apenas de uma maior "facilidade de comunicação", como se costuma pensar, mas de um maior compartilhamento de experiências, principalmente.

Migrar do risco para a vulnerabilidade, como já foi apontado, é outro importante desafio. Em termos bem sintéticos, trata-se de não centrar as políticas, programas e ações tanto em grupos identitários, ou grupos de risco, mas nas relações socialmente estabelecidas entre os diversos grupos populacionais e suas interdependentes e cambiantes identidades. Por outro lado, não tratar as práticas que expõem as pessoas ao HIV e ao adoecimento por Aids como fruto exclusivo da vontade e do grau de esclarecimento dos indivíduos, mas ver os comportamentos como a resultante final de um conjunto de condições estruturais e contextuais de onde essas práticas emergem.

É por isso que, sem desprezar as informações trazidas pelos indicadores epidemiológicos e as associações probabilísticas, é preciso orientar as ações por subsídios que não se restrinjam às "evidências" epidemiológicas e por 
ações que não se limitem a apostas na informação/modelagem dos indivíduos. É preciso um saber interdisciplinar, uma ação intersetorial e uma retro-alimentação de ambas por avaliações que tomem menos o econômico $e$ o técnico, em sentido estrito, e mais os valores e os Direitos Humanos como forma de nos perguntarmos e respondermos à questão primordial: estamos fazendo a coisa certa?

Por fim, cabe lembrar que nenhum dos caminhos apontados para o enfrentamento dos desafios da prevenção pode se apoiar na estratégia do terror. Com o terror não há o necessário diálogo entre os sujeitos; não há intersubjetividade criadora que se estabeleça; não há a politização $e$ subjetivação dos comportamentos.

Alternativas ao terror já vêm sendo desenvolvidas com sucesso pelo Programa brasileiro. As campanhas de Carnaval são um bom exemplo de como se pode fazer campanha educativa sem terror. Mas para além do Carnaval, as ações que, direta ou indiretamente, a Coordenação Nacional de DST/AIDS sustenta têm, em grande medida, privilegiado o recurso ao lúdico, ao erotismo e à problematização das diversas situações cotidianas nas quais o problema da vulnerabilidade à infecção se manifesta e este parece ser um dos segredos dos êxitos alcançados no campo da prevenção no Brasil.

\section{Para concluir}

O conjunto dos aprendizados e desafios arrolados é fruto de uma experiência contundente que irrompeu em uma Saúde Pública que, já quase ao final do século $\mathrm{XX}$, parecia não ter mais com o que se surpreender, especialmente nos países industrializados. Erros e acertos, de um lado, $e$ desafios e utopias de outro, dispostos assim numa discussão tão sumária, podem obscurecer a complexidade e dificuldade enormes dessa experiência. Por isso é preciso que se advirta que o caráter quase-esquemático que propositalmente se assumiu aqui não deve ser confundido com pedantismo crítico ou, inversamente, com ingênua candura.

Com efeito, o inventário dos conceitos e práticas em educação preventiva aqui realizado não se propôs a ser exaustivo, nem haveria espaço para se entrar em sutilezas na apreciação crítica de cada um deles. Assim, um simplismo a contragosto ao tratar dessas experiências e proposições não significa uma desqualificação rápida e presunçosa do valor e das motivações do trabalho de todos quantos têm estado envolvidos em ações preventivas nesses anos todos. A proposta foi tão somente mapear algumas das tendências principais do desenvolvimento dessas ações, de modo já interessado naquelas que, ainda que pela negativa, trouxeram aportes para críticas e reconstruções que se julgou de maior interesse ou novidade.

Destaque-se, por outro lado, que, ainda que repudiando vigorosamente o simplismo, a busca da simplicidade foi, esta sim, um valor que orientou este ensaio. Mas, não se a confunda com busca do conforto do fácil, nem com a suposição, cândida, de que um tema como o tratado coubesse docilmente num ensaio de uma dezena de páginas. $O$ que se quis evitar a todo custo foi o vício de associar inexoravelmente o poderoso ao grandioso, o complexo ao inacessível, o difícil ao indizível, o utópico ao inalcançável. Buscar traduzir o 
poderoso, complexo, difícil e utópico em formulações simples, mais que uma estratégia comunicacional, pretendeu ser uma atitude filosófica, a busca de uma perspectiva de análise que se colocasse ativamente em estreito contato com os significados mais inadvertidamente impressionantes das despretensiosas narrativas que constituem a "crônica" cotidiana da epidemia.

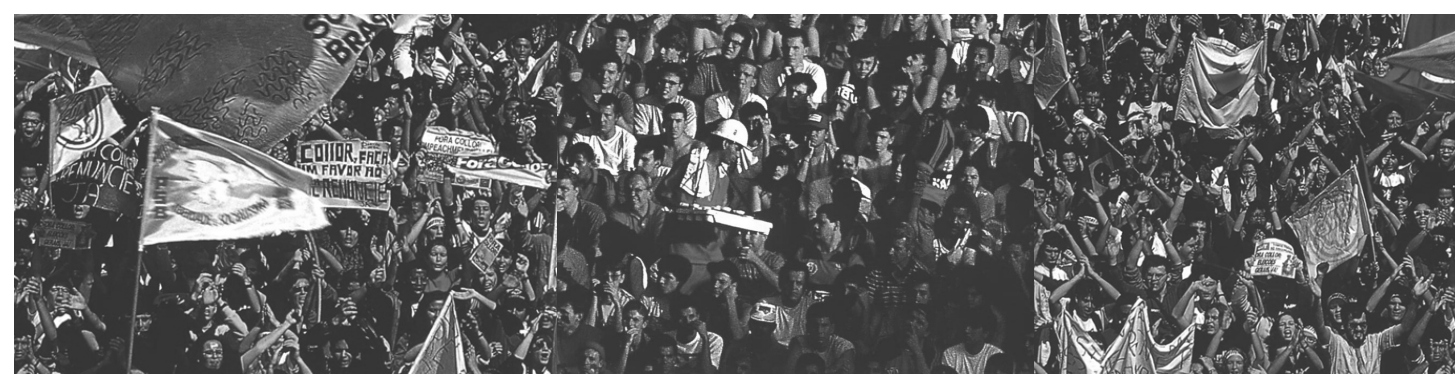

Referências

AYRES, J. R. C. M. Sobre o risco: para compreender a epidemiologia. São Paulo: Hucitec, 1997.

AYRES, J. R. C. M. Sujeito, intersubjetividade e práticas de saúde. Ciênc. Saúde Coletiva, v.6, n.1, p.6372, 2001.

AYRES, J. R. C. M.; FRANÇA JÚNIOR, I.; CALAZANS, G. J.; SALETTI FILHO, H. C. Vulnerabilidade e prevenção em tempos de Aids. In: BARBOSA, R. M.; PARKER, R. G. (Orgs.) Sexualidades pelo avesso: direitos, identidade e poder. São Paulo: Editora 34, 1999. p.49-72.

CASTELLS, M. O poder da identidade. 2.ed. Rio de Janeiro: Paz e Terra, 1999. 2.ed.

DANIEL, H. Vida antes da morte. 2.ed. Rio de Janeiro: ABIA, 1994.

ENHANCING CARE INITIATIVE. Mulheres e aids: desafios para os Serviços de Saúde. Disponível em $<$ www.eci.harvard.edu>. Acesso em: ago. 2001.

FARMER, P.; CONNORS, M.; SIMMONS, J. (Eds.) Women, poverty and AIDS: sex, drugs and structural violence. Monroe: Common Courage Press, 1996.

FREIRE, P. Pedagogia da autonomia: saberes necessários à prática educativa. 15. ed. São Paulo: Paz e Terra, 2000.

GADAMER, H. G. Verdad y método: fundamentos de una hermenéutica filosófica. Salamanca: Sígueme, 1996.

HABERMAS, J. Pensamento pós-metafísico: estudos filosóficos. Rio de Janeiro: Tempo Brasileiro, 1990. HEIDEGGER, M. Ser e tempo. 5.ed. Petrópolis: Vozes, 1995.

MANN, J.; TARANTOLA, D. AIDS in the World II. New York: Oxford University Press, 1996.

PAIVA, V. Sem mágicas soluções: a prevenção ao HIV e à Aids como um processo de Emancipação psicossocial. In: SEMINÁRIO PREVENÇÃO À AIDS: LIMITES E POSSIBILIDADES NA TERCEIRA DÉCADA. 2002. Rio de Janeiro. Anais... Rio de Janeiro: ABIA, 2002. p.20-7.

PARKER, R. G. Na contramão da AIDS: sexualidade, intervenção, política. Rio de Janeiro: ABIA, São Paulo: Editora 34, 2000.

PARKER, R.; CAMARGO JÚNIOR, K. R. Pobreza e HIV/AIDS: aspectos antropológicos e sociológicos. Cad. Saúde Pública, v.16, supl.1, p.89-102, 2000.

RICOEUR, P. O si mesmo como um outro. Campinas: Papirus, 1991.

RORTRY, R. A Filosofia e o espelho da natureza. Lisboa: D. Quixote, 1988. 
SEFFNER, F. Prevenção à AIDS: uma ação político-pedagógica. In: SEMINÁRIO PREVENÇÃO À AIDS: LIMITES E POSSIBILIDADES NA TERCEIRA DÉCADA. 2002. Rio de Janeiro. Anais... Rio de Janeiro: ABIA, 2002. p.28-38.

SOUZA, H. A cura da Aids. Rio de Janeiro: Relume-Dumará, 1994.

TREICHLER, P. AIDS, homophobia and biomedical discourse: an epidemic of signification. In: CRIMP, D. (Ed.) AIDS: Cultural analysis, cultural activism. Cambridge: The MIT Press, 1988. p.31-70.

AYRES, J.R.C.M. Prácticas educativas y prevención de HIV/SIDA: lecciones aprendidas y desafíos actuales, Interface _ Comunic, Saúde, Educ, v.6, n.11, p.11-24, 2002.

La prevención ha sido una cuestión crucial para los programas de control del SIDA. Los enormes progresos del conocimiento y de la técnica en este campo no llegaron a alterar sustantivamente los determinantes fundamentales de la infección y el proceso de enfermedad de significativos contingentes poblacionales. Este ensayo pretende sistematizar las lecciones que aprendimos del campo de la prevención en estas dos décadas de epidemia, tomando como base, especialmente, la experiencia brasileña. Se juzga que fueron básicamente cuatro las grandes lecciones aprendidas: a) el terrorismo no funciona; b) el riesgo es un concepto útil, pero limitado; c) la prevención no se enseña (sino que se aprende); d) no somos sin un Otro, somos inmediatamente intersubjetividades. Las implicaciones de estas lecciones para nuestras estrategias de prevención son, en síntesis: a) que debemos pensarlas menos en términos de "grupos poblacionales" y mucho más en lo que podemos llamar de "contextos de intersubjetividad"; lo que significa, delimitar espacios de interacción (sociales, culturales etc.) generadores de vulnerabilidad y, de forma articulada, los contextos intersubjetivos favorables a la construcción de las respuestas para una reducción de esas vulnerabilidades; b) la efectiva substitución de la actitud modeladora por una actitud emancipadora en nuestras prácticas educativas; c) no centrar las políticas, programas y acciones en los grupos de riesgo o en los comportamientos de riesgo, y sí hacerlo en las relaciones socialmente establecidas entre los diversos sujetos sociales y sus interdependientes y cambiantes identidades.

PALABRAS CLAVE: Síndrome de inmunodeficiencia adquirida; educación en salud. 
AYRES, J. R. C. M.
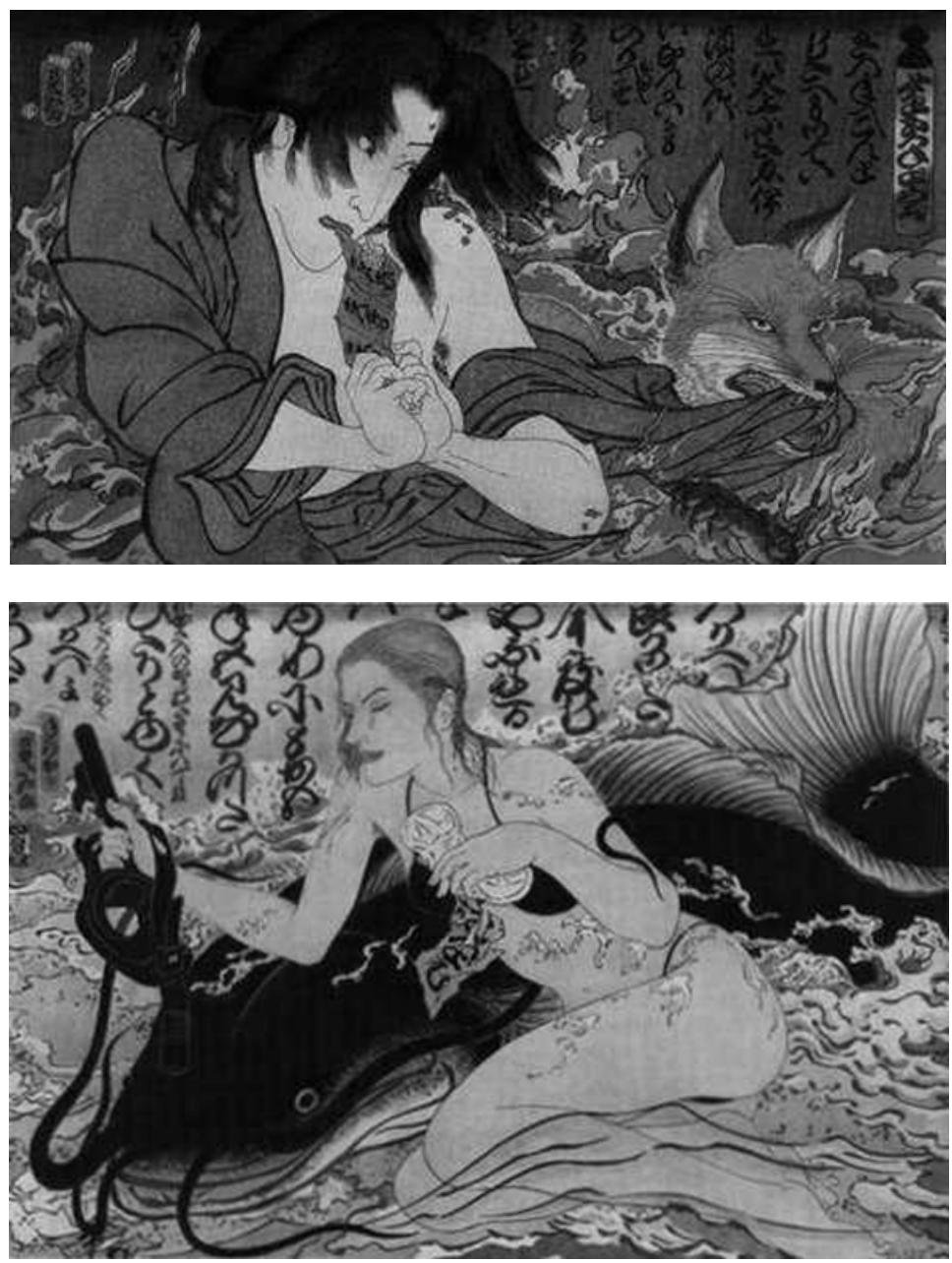

TERAOKA, Série Aids 